\title{
Neo-deterministic seismic hazard assessment of Corsica-Sardinia block
}

\author{
Enrico Brandmayr ${ }^{1,2}$ (]) Franco Vaccari ${ }^{1} \cdot$ Giuliano Francesco Panza ${ }^{2,3,4,5,6}$
}

Received: 18 August 2021 / Accepted: 7 October 2021 / Published online: 18 October 2021

(c) The Author(s) 2021

\begin{abstract}
The Corsica-Sardinia lithospheric block is commonly considered as a region of very low seismicity and the scarce reported seismicity for the area has till now precluded the reliable assessment of its seismic hazard. The time-honored assumption has been recently questioned and the historical seismicity of Sardinia has been reevaluated. Even more, several seismogenic nodes capable of M5 + have been recognized in the Corsica-Sardinia block exploiting the morphostructural zonation technique, calibrated to earlier results obtained for the Iberian peninsula, which has structural lithospheric affinities with the Corsica-Sardinia block. All this allows now for the computation of reliable earthquake hazard maps at bedrock conditions exploiting the power of Neo Deterministic Seismic Hazard Assessment (NDSHA) evaluation. NDSHA relies upon the fundamental physics of wave generation and propagation in complex geologic structures and generates realistic time series from which several earthquake ground motion parameters can be readily extracted. NDSHA exploits in an optimized way all the available knowledge about lithospheric mechanical parameters, seismic history, seismogenic zones and nodes. In accordance with continuum mechanics, the tensor nature of earthquake ground motion is preserved computing realistic signals using structural models obtained by tomographic inversion and earthquake source information readily available in literature. The way to this approach has been open by studies focused on continental Italy and Sicily, where the agreement between hazard maps obtained using seismogenic zones, informed by earthquake catalog data, and the maps obtained using only seismogenic nodes are very good.
\end{abstract}

Keywords Corsica-Sardinia block $\cdot$ Seismic hazard $\cdot$ NDSHA $\cdot$ MSZ

Enrico Brandmayr

ebrandmayr@units.it

Franco Vaccari

vaccari@units.it

Giuliano Francesco Panza

giulianofpanza@fastwebnet.it

1 Department of Mathematics and Geosciences, University of Trieste, 34128 Trieste, Italy

2 Accademia Nazionale dei Lincei, Rome, Italy

3 Institute of Geophysics, China Earthquake Administration, Beijing, China

4 Accademia Nazionale delle Scienze detta dei XL, Rome, Italy

5 International Seismic Safety Organization, ISSO, Arsita, Italy

6 Beijing University of Civil Engineering and Architecture (BUCEA), Beijing, China

\section{Introduction}

In contrast to the neighboring Apennine Peninsula, the seismic history of the Corsica-Sardinia region, reported by earthquake catalogs, is characterized by sporadic and weak shocks, magnitudes of which, as a rule, do not exceed 5 (Rovida et al. 2020, 2021; Postpischl 1985). Meletti et al (2021) concluded that Sardinia island is "not earthquakeless" and contradict the time-honored assumption. The recent instrumental observations evidence the ongoing low seismic activity in the region: specifically, during 2020 the INGV seismic network recorded four small shocks in Sardinia (http://terremoti.ingv.it). The very scarce seismicity reported in official documents (parametric catalogs and historical records, Table 2) prevented till now a reliable assessment of earthquake hazard of the single Sardinia-Corsica lithospheric block, characterized by a common geodynamic evolution (Minzoni 1991). In a recent paper Gorshkov et al. (2021) evaluated the seismic potential of the region employing the morphostructural zoning (MSZ) that allows 
for the identification of the location of potential earthquakes independently from the seismic history just relying on the systematic and quantitative analysis of the available geological and morphostructural data. The MSZ delineates the hierarchical system of morphostructural blocks, the network of lineaments bounding the blocks, and the loci of nodes formed around intersections of lineaments. Nodes are treated as earthquake controlling structures (Gorshkov et al. 2003). Their seismic potential is evaluated exploiting the existing criteria of seismicity defined earlier for seismogenic (M5+) nodes in Iberia, whose structural setting is grossly similar to the one of the Corsica-Sardinia block (Raykova and Panza 2010; Panza et al. 2007; Carminati et al. 2012). 24 out of the 81 nodes delineated by MSZ meet the characteristic features (criteria of seismicity) of the seismogenic nodes prone to M5 + that have been defined by pattern recognition in the Iberian Peninsula (Gorshkov et al. 2010). The study by Gorshkov et al. (2021) suggests that the seismic potential of the Corsica-Sardinia block is not low and provides the key information for long-term reliable seismic hazard assessment of the region and motivates the application of the Neo Deterministic Seismic Hazard Assessment (NDSHA) to reliably evaluate the earthquake hazard of the study area.

\section{Methodology and data}

NDSHA (Panza et al. 2001a, b, 2012; Panza and Bela 2020; Bela and Panza 2021; Panza et al. 2021) is a now well established technique based on the physical description of the earthquake rupture process and of the seismic propagation paths aimed to obtain synthetic seismograms from which reliable ground motion parameters relevant to engineering applications can be extracted even when the available records are very poor. NDSHA exploits all the known seismicity and other potential seismic sources and the available knowledge of the Earth structure (i.e. the propagation medium, the ray-path), preserving the tensor nature of earthquake ground motion (Aki and Richards 2002). While ground motion parameters at the regional scale are given, as a rule, for bedrock conditions, more detailed studies can be performed at specific sites, taking into account the nature of local soil and the rupture complexity at the source. We refer the reader to previous works for a detailed description of the theoretical and computational workflow of NDSHA (e.g. Panza et al. 2001a, b, 2012; Panza and Bela 2020; Bela and Panza 2021; Panza et al. 2021), while in the following we describe the input data and the procedural steps applied in this study.

No seismogenic zones (Meletti et al. 2008) have been defined for the study area, thus we use only the seismogenic nodes identified by MSZ as seismic sources (Fig. 1), such approach being proven valid by Rugarli et al. (2019) for continental Italy and Sicily. The nodes are prone to M5 + earthquakes (Gorshkov et al. 2021), thus we assign $M_{\mathrm{W}}=5$ to all sources that are uniformly distributed within the nodes of $25 \mathrm{~km}$ of radius (Fig. 2), at a fixed depth of $10 \mathrm{~km}$.

Very little information about the focal mechanisms of earthquake sources in the study area is available and the few mechanisms that have been determined mostly fall outside the nodes. Therefore, we associate to each node a representative average focal mechanism determined by Pondrelli et al. (2020) for the Sardinia-Corsica Block. Of this mechanism we retain dip and rake angles, while the strike is chosen according to the orientation of the higher rank lineament intercepted by each node (Fig. 2). Anyway, using the average strike for all the nodes brings typically consistent results, so the latter will not be presented in the following section.

The regional structure that is used as propagation medium is described by a set of $1 \mathrm{D}$ an elastic seismic cellular models (Fig. 3 and Table 2) with a resolution of $1^{\circ} \times 1^{\circ}$ (Brandmayr et al. 2010; Brandmayr 2012) obtained from surface wave tomography down to 350 of depth, while a standard reference structure (Kennett and Engdahl 1991) was used at larger depths.

Regional hazard maps are computed using the Size Scaled Point Source model (SSPS, after Parvez et al. 2011) approximation. The Design Ground Acceleration (DGA) is obtained considering appropriate response spectra (Panza et al. 2001a, b), specifically the Eurocode 8 (CEN 2004) response spectrum for soil type A.

\section{Results and discussion}

Vertical displacement map show widespread low values on both Corsica and Sardinia $(<0.1 \mathrm{~cm})$. Similarly, vertical velocities are everywhere $<0.5 \mathrm{~cm} / \mathrm{s}$ and vertical DGAs are $<0.005$ g (Fig. 4, top). Horizontal components are slightly higher: horizontal displacement tops $0.5 \mathrm{~cm}$ in most of Corsica and eastern Sardinia; horizontal velocities reach $1 \mathrm{~cm} / \mathrm{s}$ on the western coast of Corsica and the Cagliari area; horizontal DGAs reach $0.01 \mathrm{~g}$ in Corsica and eastern Sardinia (Fig. 4, bottom).

These values are consistent with $I=\mathrm{V}$ (MCS, applying the regression after Panza et al. (2001a, b) reported for most of the historical events felt in the area (Meletti et al. 2021). However, Meletti et al. (2021) also report $I=$ VI caused by the 1948-1949 seismic sequence with epicentral area in NW Sardinia.

$M_{\mathrm{W}}=5$ is the lower bound of the magnitude threshold identified by the pattern recognition methodology. Thus, following Rugarli et al. (2019), in a second run we increase the source magnitude to $M_{\mathrm{W}}=5.5$, applying an increment defined as $\Delta M=\gamma_{\mathrm{EM}} \sigma_{\mathrm{M}}$, where $\gamma_{\mathrm{EM}}$ (here set to 2.0) is a 
Fig. 1 Map of the study area with morphostructural zonation after Gorshkov et al. (2021).

Thick lines are the lineaments of the first rank, medium lines are the lineaments of the second rank, thin lines are the lineaments of the third rank; continuous lines represent the longitudinal lineaments; dashed ones represent the transverse lineaments. Seismogenic nodes prone to $M \geq 5$ earthquakes are marked by red circles. Green large dots denote epicenters of earthquakes with $M \geq 5.0$, while green small dots depict epicenters of earthquakes with $4.0 \leq M<5.0$, after CPTI15 catalog (https://emidius.mi.ingv. it/CPTI15-DBMI15). For seismic events details see Table 1 .

Color figure online nodes.poc

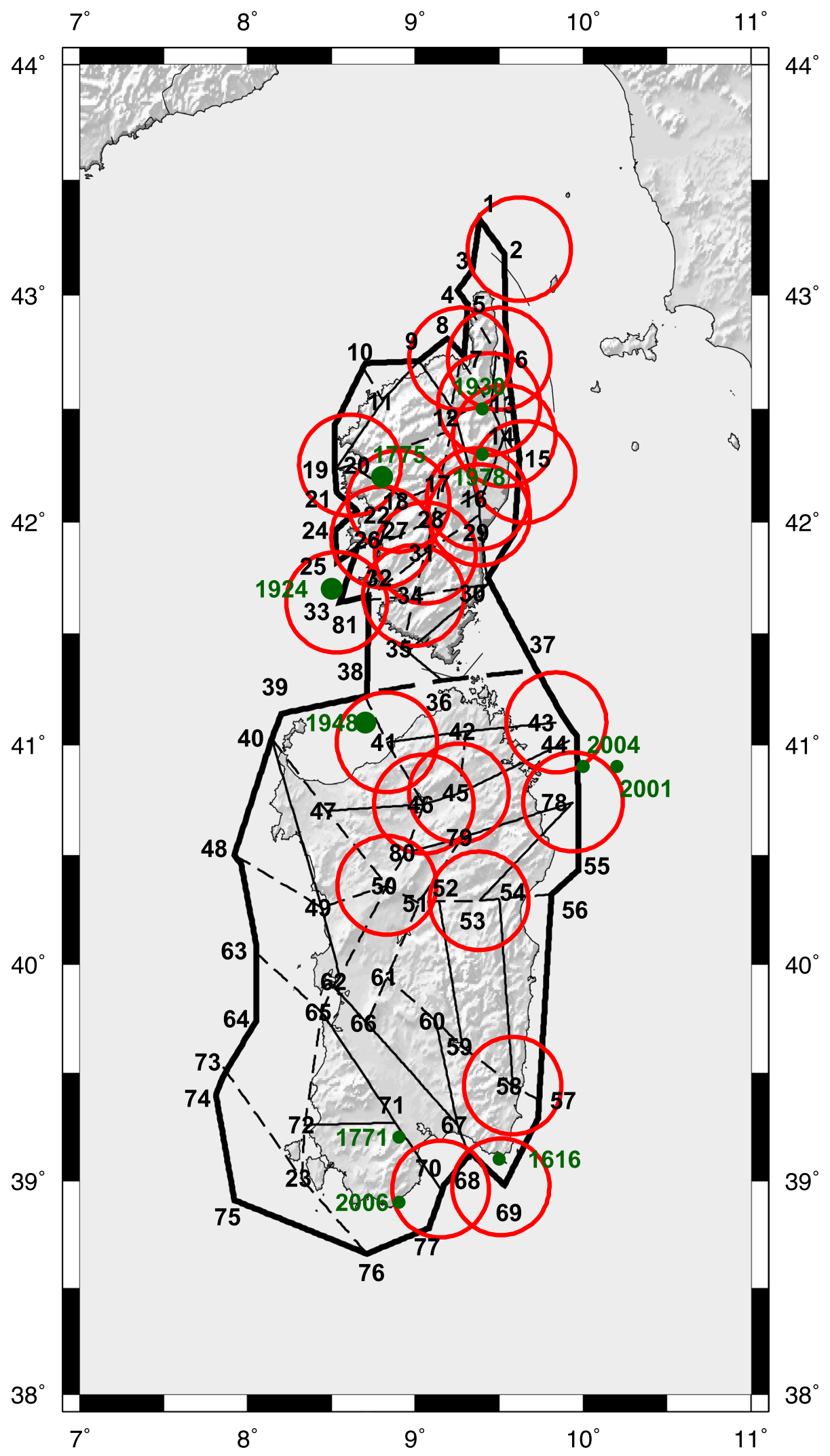


Table 1 Earthquakes M4+in the Corsica-Sardinia region after the CPTI15 (after Gorshkov et al. 2021). Events with $M \geq 5$ are marked in bold

\begin{tabular}{|c|c|c|c|c|c|}
\hline Date & Lat & Long & M & $I$ & CPTI15 ID \\
\hline 16160604 & $39.1 \mathrm{~N}$ & $9.5 \mathrm{E}$ & Mw4.9 & & Sardegna merid \\
\hline 17710817 & $39.2 \mathrm{~N}$ & $8.9 \mathrm{E}$ & Mw 4.4 & V & Sardegna merid \\
\hline 17751022 & $42.2 \mathrm{~N}$ & $8.8 \mathrm{E}$ & Mw5.1 & & Vico (Corsica) \\
\hline 19240124 & $41.7 \mathrm{~N}$ & $8.5 \mathrm{E}$ & Mw5.0 & & Sardegna nord-occ \\
\hline 19300208 & $42.5 \mathrm{~N}$ & $9.4 \mathrm{E}$ & Mw 4.5 & & Castagniccia \\
\hline 19481113 & $41.1 \mathrm{~N}$ & $8.7 \mathrm{E}$ & Mw5.1 & V-VI & Mar di Sardegna \\
\hline 19780403 & $42.3 \mathrm{~N}$ & $9.4 \mathrm{E}$ & Mw 4.5 & & Corsica \\
\hline 20010303 & $40.9 \mathrm{~N}$ & $10.0 \mathrm{E}$ & Mw4.1 & & $\begin{array}{l}\text { Tirreno centrale } \\
\text { (MARE) }\end{array}$ \\
\hline 20041218 & $40.9 \mathrm{~N}$ & $10.2 \mathrm{E}$ & ML4.3 & & $\begin{array}{l}\text { Tirreno centrale } \\
\text { (MARE) }\end{array}$ \\
\hline 20060324 & $38.9 \mathrm{~N}$ & $8.9 \mathrm{E}$ & Mw4.0 & & Capo Teulada \\
\hline
\end{tabular}

When available, maximum felt intensity $(I)$ has been added from Meletti et al. (2021)

tunable safety factor, variable from 1.5 to 2.5 (Rugarli et al 2019), and $\sigma_{M}$ (here set to 0.25 ) is a value representative of the global uncertainty on magnitude determination $0.2-0.3$ (Båth 1973). We refer to the incremented magnitude value as $M_{\text {design }}$.
Maps obtained in such a way (second run) show vertical displacement up to $0.5 \mathrm{~cm}$ in the whole study area, vertical velocities up to $1 \mathrm{~cm} / \mathrm{s}$ in most of Corsica and interior of Sardinia and vertical DGAs up to $0.02 \mathrm{~g}$ in SW Corsica and, locally, in western Sardinia (Fig. 5, top).

Horizontal displacement reaches $2 \mathrm{~cm}$ in central-western Corsica; horizontal velocities reach $4 \mathrm{~cm} / \mathrm{s}$ in W Corsica and Cagliari area, while are generally over $1 \mathrm{~cm} / \mathrm{s}$ in most of the study area; horizontal DGAs can be as high as $0.04 \mathrm{~g}$ in most of the study area excepted $\mathrm{W}$ coast of Sardinia (Fig. 5, bottom). These values correspond to $I=\mathrm{VII}$ on the MCS scale (Panza et al. 2001a, b).

In our opinion, the second run supplies a reliable and conservative description of the actual seismic hazard of Corsica-Sardinia block, also on account of the scarce empirical knowledge of the seismicity of the area, including major uncertainties on the focal depth and mechanisms of the earthquakes.

Rugarli et al (2019) applied $M_{\text {design }}$ to the rest of the Italian territory considering only seismogenic nodes and obtained hazard maps in agreement with those based on seismogenic zones and the CPTI04 catalog. Brandmayr et al. (2021) showed that the application of $M_{\text {design }}$ (at $1 \mathrm{~Hz}$ cut-off frequency) in Kosovo gives hazard levels consistent with $10 \mathrm{~Hz}$ cut-off frequency computation, which needs
Fig. 2 Map of the seismogenic nodes with associated magnitude, representative focal mechanism (left) and location of the sources within the nodes (right) sarcm.nod

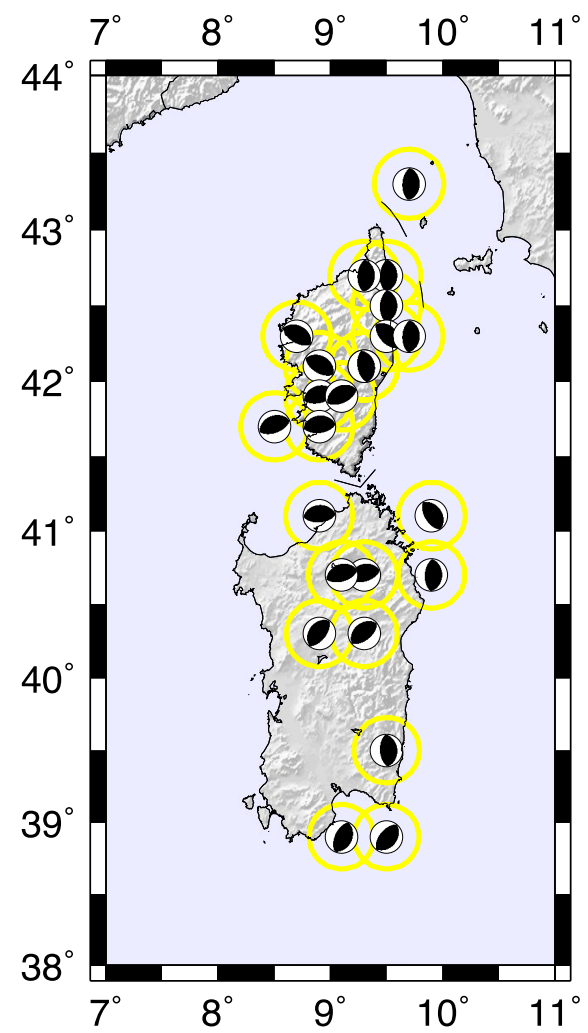

sarcm.und

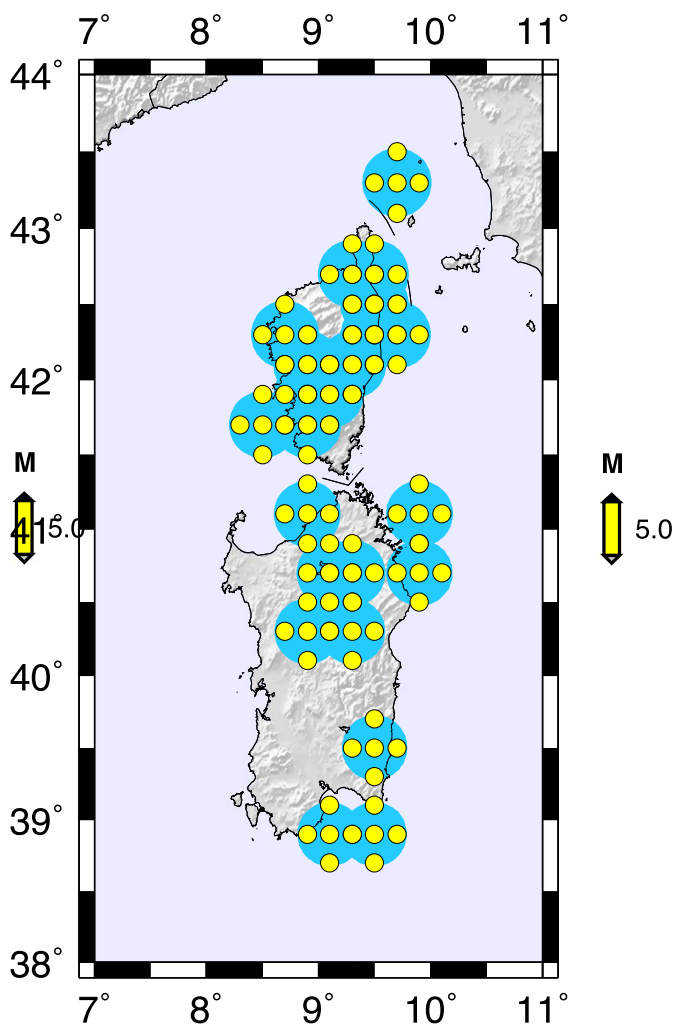



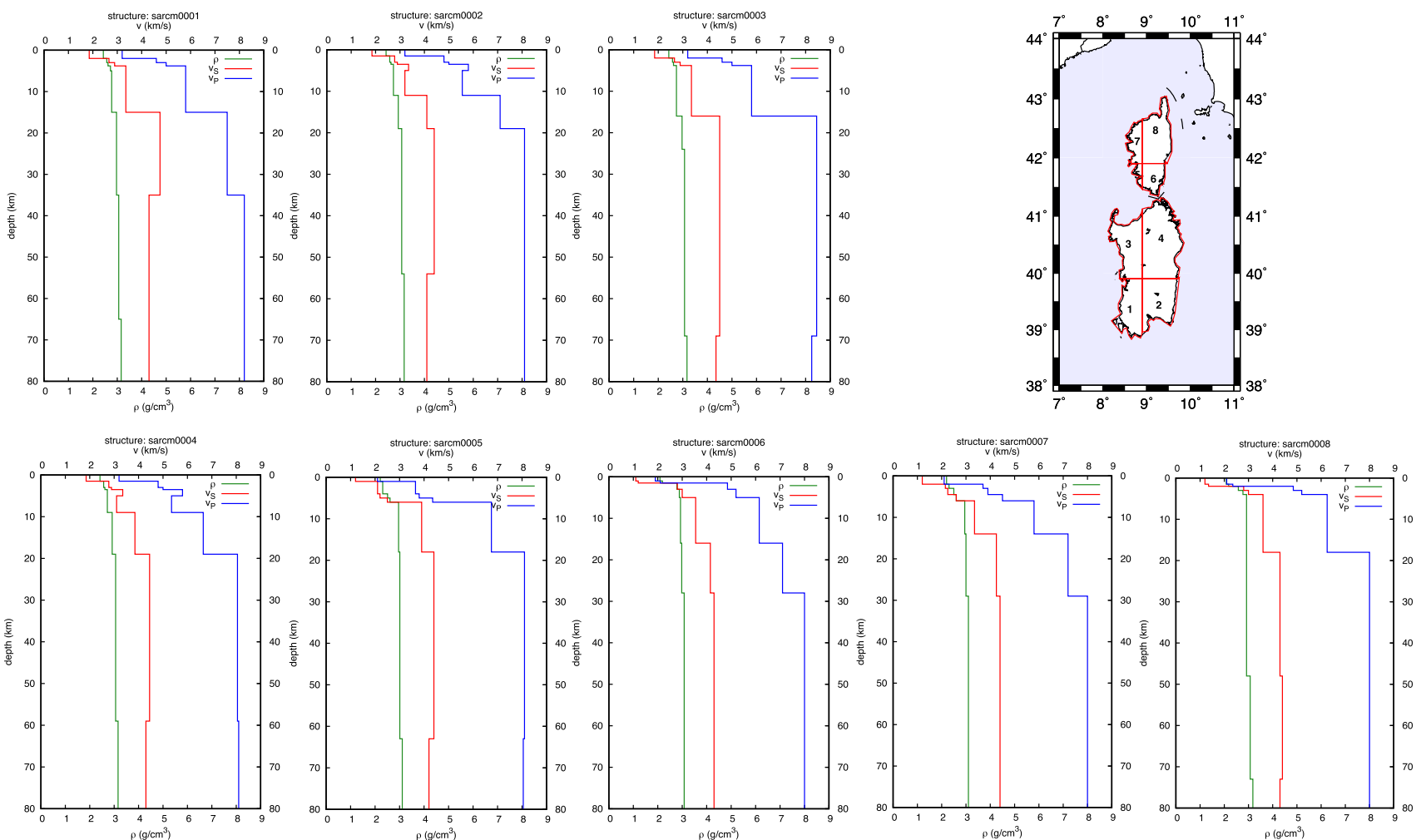

Fig. 3 Structural cellular models of the study area (after Brandmayr 2012) down to 8o km of depth. Models are coded with progressive numbers as shown in the inset map. $\rho$ is density (color figure online). For details of structural models down to $350 \mathrm{~km}$, see Table 2

a knowledge of sources and structures with a detail not available for the study area.

Therefore, we consider the ground motion maps obtained applying $M_{\text {design }}$ the most, now possible, reliable advancement in the understanding of the seismic hazard of the area. $M_{\text {design }}$ is a readily available tool for assessing and mitigating seismic risk, especially where critical infrastructures (e.g. rad-waste surface disposal facility, natural-gas pipelines, etc.) may be planned.

\section{Conclusions}

NDSHA relies upon the fundamental physics of wave generation and propagation in complex geologic structures to generate realistic synthetic seismograms, used as input for the computation of several ground motion parameters, integrating all the available knowledge about seismic sources and medium structure. Seismogenic nodes identified in the Corsica-Sardinia block by Gorshkov et al. (2021) supply information about the seismic potential of the study area filling the gap due to the scarce and poorly known seismic history of the area and allow for the assessment of seismic hazard using NDSHA.

Considering seismogenic nodes in Italy, Rugarli et al. (2019), showed that adding a safety increment $\Delta M$ is equivalent to applying a partial safety factor $\gamma_{\mathrm{q}}$ to the seismic moment at the fault $M_{0}$, as normally asked by Eurocodes and other international standards for typical structural design. Ground motion estimates so obtained envelope the ones obtained using the seismic catalog. Similarly, we suggest that the application of seismogenic nodes and $M_{\text {design }}=5.5$ to Corsica-Sardinia block provides the most reliable assessment of seismic hazard of the area so far.

In particular, we show that large portions of Corsica and Sardinia could experience ground motion levels compatible with $I=$ VII on the MCS macroseismic intensity scale. Such macroseismic intensity envelopes the values felt and documented so far, pointing out that some further actions of prevention and mitigation of seismic risk should be enforced, especially in the siting of critical infrastructures. 
Table 2 Structural models used in this study (after Brandmayr 2012) down to a depth of $350 \mathrm{~km}$

\begin{tabular}{|c|c|c|c|c|c|c|}
\hline Thk (km) & $\rho\left(\mathrm{g} / \mathrm{cm}^{3}\right)$ & $V_{\mathrm{P}}(\mathrm{km} / \mathrm{s})$ & $V_{\mathrm{S}}(\mathrm{km} / \mathrm{s})$ & $Q_{\mathrm{P}}$ & $Q_{\mathrm{S}}$ & $Z(\mathrm{~km})$ \\
\hline \multicolumn{7}{|c|}{$8.5^{\circ}$ E $39.50^{\circ} \mathrm{N}-01$} \\
\hline 2.00 & 2.43 & 3.20 & 1.85 & 638 & 290 & 2.00 \\
\hline 1.00 & 2.57 & 4.60 & 2.66 & 638 & 290 & 3.00 \\
\hline 0.80 & 2.62 & 5.00 & 2.89 & 616 & 280 & 3.80 \\
\hline 1.20 & 2.72 & 5.80 & 3.35 & 616 & 280 & 5.00 \\
\hline 10.00 & 2.77 & 5.80 & 3.35 & 506 & 230 & 15.00 \\
\hline 20.00 & 2.97 & 7.50 & 4.75 & 286 & 130 & 35.00 \\
\hline 30.00 & 3.06 & 8.20 & 4.30 & 176 & 80 & 65.00 \\
\hline 95.00 & 3.16 & 8.20 & 4.30 & 176 & 80 & 160.00 \\
\hline 110.00 & 3.28 & 8.20 & 4.30 & 220 & 100 & 270.00 \\
\hline 80.00 & 3.50 & 8.85 & 4.75 & 330 & 150 & 350.00 \\
\hline \multicolumn{7}{|c|}{$9.5^{\circ}$ E $39.5^{\circ} \mathrm{N}-02$} \\
\hline 1.50 & 2.43 & 3.20 & 1.85 & 638 & 290 & 1.50 \\
\hline 1.50 & 2.58 & 4.80 & 2.78 & 638 & 290 & 3.00 \\
\hline 0.50 & 2.63 & 5.00 & 2.89 & 616 & 280 & 3.50 \\
\hline 1.50 & 2.73 & 5.80 & 3.35 & 616 & 280 & 5.00 \\
\hline 6.00 & 2.73 & 5.55 & 3.20 & 550 & 250 & 11.00 \\
\hline 8.00 & 2.93 & 7.10 & 4.10 & 462 & 210 & 19.00 \\
\hline 35.00 & 3.07 & 8.10 & 4.40 & 176 & 80 & 54.00 \\
\hline 40.00 & 3.17 & 8.10 & 4.10 & 176 & 80 & 94.00 \\
\hline 160.00 & 3.28 & 8.55 & 4.45 & 220 & 100 & 254.00 \\
\hline 96.00 & 3.49 & 8.85 & 4.75 & 330 & 150 & 350.00 \\
\hline \multicolumn{7}{|c|}{$8.5^{\circ} \mathrm{E} 40.5^{\circ} \mathrm{N}-03$} \\
\hline 2.00 & 2.43 & 3.20 & 1.85 & 638 & 290 & 2.00 \\
\hline 1.00 & 2.58 & 4.60 & 2.66 & 638 & 290 & 3.00 \\
\hline 0.80 & 2.62 & 5.00 & 2.89 & 616 & 280 & 3.80 \\
\hline 12.20 & 2.74 & 5.80 & 3.35 & 484 & 220 & 16.00 \\
\hline 8.00 & 2.97 & 8.45 & 4.50 & 396 & 180 & 24.00 \\
\hline 45.00 & 3.07 & 8.45 & 4.50 & 176 & 80 & 69.00 \\
\hline 90.00 & 3.17 & 8.25 & 4.35 & 176 & 80 & 159.00 \\
\hline 110.00 & 3.28 & 8.50 & 4.50 & 220 & 100 & 269.00 \\
\hline 81.00 & 3.50 & 8.75 & 4.75 & 330 & 150 & 350.00 \\
\hline \multicolumn{7}{|c|}{$9.5^{\circ} \mathrm{E} 40.5^{\circ} \mathrm{N}-04$} \\
\hline 1.50 & 2.42 & 3.20 & 1.85 & 638 & 290 & 1.50 \\
\hline 1.50 & 2.57 & 4.80 & 2.78 & 638 & 290 & 3.00 \\
\hline 0.50 & 2.62 & 5.00 & 2.89 & 616 & 280 & 3.50 \\
\hline 1.50 & 2.72 & 5.80 & 3.35 & 616 & 280 & 5.00 \\
\hline 4.00 & 2.72 & 5.35 & 3.10 & 572 & 260 & 9.00 \\
\hline 10.00 & 2.92 & 6.65 & 3.85 & 462 & 210 & 19.00 \\
\hline 40.00 & 3.06 & 8.05 & 4.45 & 176 & 80 & 59.00 \\
\hline 80.00 & 3.16 & 8.10 & 4.30 & 176 & 80 & 139.00 \\
\hline 160.00 & 3.27 & 8.70 & 4.55 & 220 & 100 & 299.00 \\
\hline 51.00 & 3.49 & 8.80 & 4.75 & 330 & 150 & 350.00 \\
\hline \multicolumn{7}{|c|}{$8.5^{\circ} \mathrm{E} 41.5^{\circ} \mathrm{N}-05$} \\
\hline 1.00 & 2.21 & 2.10 & 1.20 & 572 & 260 & 1.00 \\
\hline 3.00 & 2.31 & 3.65 & 2.10 & 572 & 260 & 4.00 \\
\hline 1.00 & 2.51 & 3.80 & 2.20 & 550 & 250 & 5.00 \\
\hline 1.00 & 2.61 & 4.35 & 2.50 & 550 & 250 & 6.00 \\
\hline 12.00 & 2.96 & 6.75 & 3.90 & 418 & 190 & 18.00 \\
\hline 45.00 & 3.01 & 8.10 & 4.40 & 176 & 80 & 63.00 \\
\hline 50.00 & 3.11 & 8.05 & 4.20 & 176 & 80 & 113.00 \\
\hline
\end{tabular}


Table 2 (continued)

\begin{tabular}{|c|c|c|c|c|c|c|}
\hline Thk (km) & $\rho\left(\mathrm{g} / \mathrm{cm}^{3}\right)$ & $V_{\mathrm{P}}(\mathrm{km} / \mathrm{s})$ & $V_{\mathrm{S}}(\mathrm{km} / \mathrm{s})$ & $Q_{\mathrm{P}}$ & $Q_{\mathrm{S}}$ & $Z(\mathrm{~km})$ \\
\hline 45.00 & 3.20 & 8.10 & 4.40 & 176 & 80 & 158.00 \\
\hline 105.00 & 3.30 & 8.40 & 4.45 & 440 & 200 & 263.00 \\
\hline 87.00 & 3.52 & 8.70 & 4.75 & 330 & 150 & 350.00 \\
\hline \multicolumn{7}{|c|}{$9.5^{\circ} \mathrm{E} 41.5^{\circ} \mathrm{N}-06$} \\
\hline 1.00 & 2.09 & 1.90 & 1.10 & 616 & 280 & 1.00 \\
\hline 0.50 & 2.19 & 2.10 & 1.20 & 616 & 280 & 1.50 \\
\hline 1.50 & 2.78 & 4.85 & 2.80 & 594 & 270 & 3.00 \\
\hline 2.00 & 2.88 & 5.20 & 3.00 & 572 & 260 & 5.00 \\
\hline 11.00 & 2.93 & 6.15 & 3.55 & 462 & 210 & 16.00 \\
\hline 12.00 & 2.98 & 7.10 & 4.15 & 330 & 150 & 28.00 \\
\hline 70.00 & 3.08 & 8.00 & 4.30 & 176 & 80 & 98.00 \\
\hline 70.00 & 3.17 & 8.15 & 4.35 & 176 & 80 & 168.00 \\
\hline 105.00 & 3.27 & 8.50 & 4.55 & 440 & 200 & 273.00 \\
\hline 77.00 & 3.50 & 8.75 & 4.75 & 330 & 150 & 350.00 \\
\hline \multicolumn{7}{|c|}{$8.5^{\circ} \mathrm{E} 42.5^{\circ} \mathrm{N}-07$} \\
\hline 2.00 & 2.20 & 2.10 & 1.20 & 374 & 170 & 2.00 \\
\hline 1.00 & 2.30 & 3.70 & 2.15 & 374 & 170 & 3.00 \\
\hline 1.50 & 2.50 & 3.90 & 2.25 & 352 & 160 & 4.50 \\
\hline 1.50 & 2.60 & 4.50 & 2.60 & 352 & 160 & 6.00 \\
\hline 8.00 & 2.95 & 5.80 & 3.35 & 308 & 140 & 14.00 \\
\hline 15.00 & 3.00 & 7.20 & 4.25 & 220 & 100 & 29.00 \\
\hline 65.00 & 3.10 & 8.00 & 4.40 & 176 & 80 & 94.00 \\
\hline 75.00 & 3.21 & 8.10 & 4.35 & 176 & 80 & 169.00 \\
\hline 100.00 & 3.32 & 8.45 & 4.65 & 440 & 200 & 269.00 \\
\hline 81.00 & 3.54 & 8.75 & 4.75 & 330 & 150 & 350.00 \\
\hline \multicolumn{7}{|c|}{$9.5^{\circ} \mathrm{E} 42.5^{\circ} \mathrm{N}-08$} \\
\hline 1.50 & 2.08 & 2.10 & 1.20 & 396 & 180 & 1.50 \\
\hline 0.50 & 2.18 & 2.35 & 1.35 & 396 & 180 & 2.00 \\
\hline 1.00 & 2.58 & 4.85 & 2.80 & 396 & 180 & 3.00 \\
\hline 1.00 & 2.77 & 5.20 & 3.00 & 396 & 180 & 4.00 \\
\hline 14.00 & 2.92 & 6.25 & 3.60 & 308 & 140 & 18.00 \\
\hline 30.00 & 2.92 & 8.00 & 4.30 & 176 & 80 & 48.00 \\
\hline 25.00 & 3.07 & 8.00 & 4.40 & 176 & 80 & 73.00 \\
\hline 70.00 & 3.18 & 8.00 & 4.30 & 176 & 80 & 143.00 \\
\hline 120.00 & 3.29 & 8.40 & 4.45 & 440 & 200 & 263.00 \\
\hline 87.00 & 3.51 & 8.80 & 4.75 & 330 & 150 & 350.00 \\
\hline
\end{tabular}

Coordinates refer to the center of $1^{\circ} \times 1^{\circ}$ cells. $Q_{\mathrm{S}}$ after Martinez et al. $(2009,2010) . Q_{\mathrm{P}}=2.2^{*} Q_{\mathrm{S}}$ 

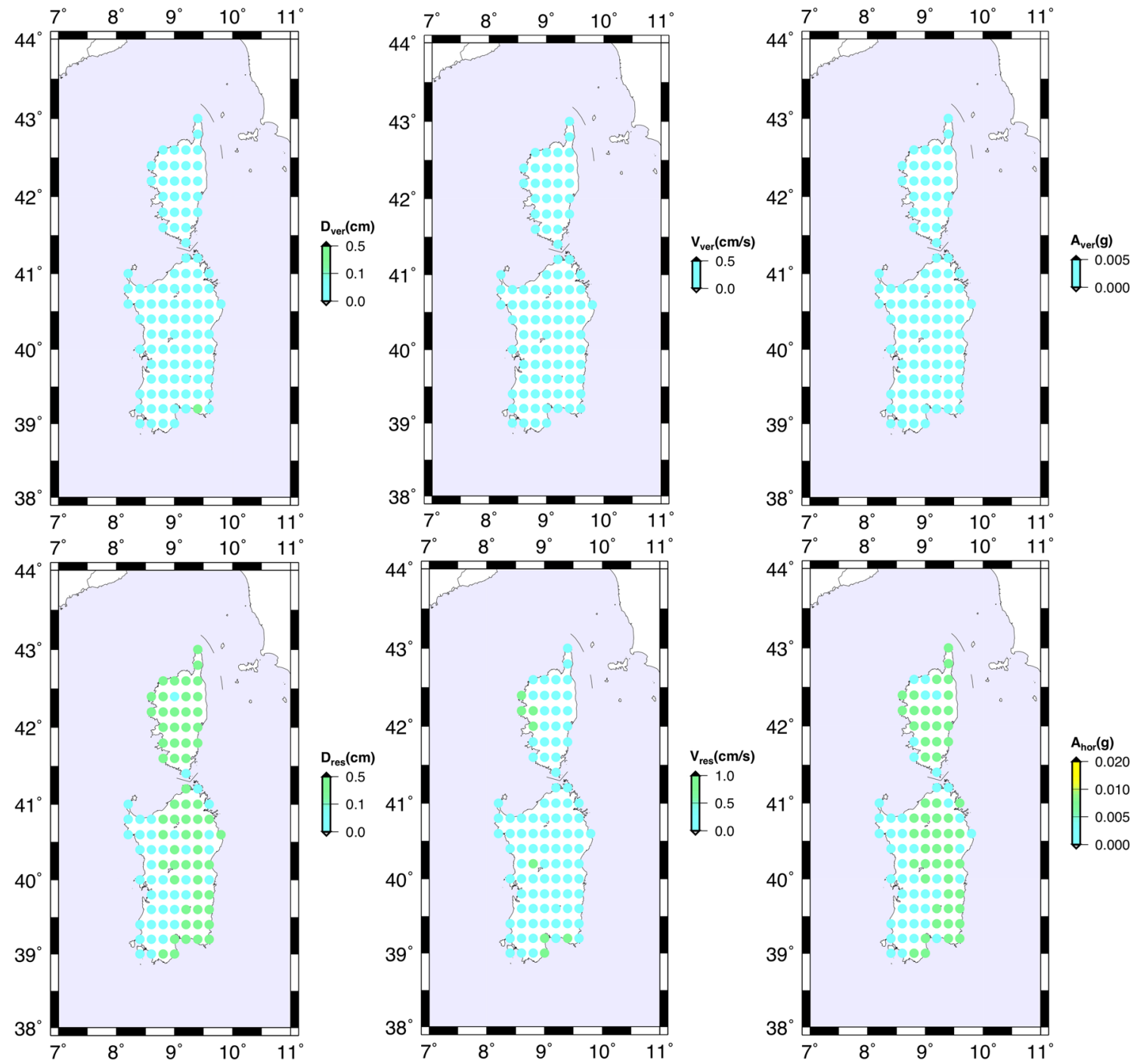

Fig. 4 Hazard maps at $1 \mathrm{~Hz}$ cut-off frequency. Top: vertical component; bottom: horizontal component (computed as the resultant of the NS and EW components for displacement and velocity). Acceleration values are obtained using Eurocode 8 (Soil A) to extrapolate the DGA at $T=0 \mathrm{~s}$. Horizontal DGA is evaluated considering either the NS or the EW accelerogram, whichever leads to the highest DGA (color figure online) 

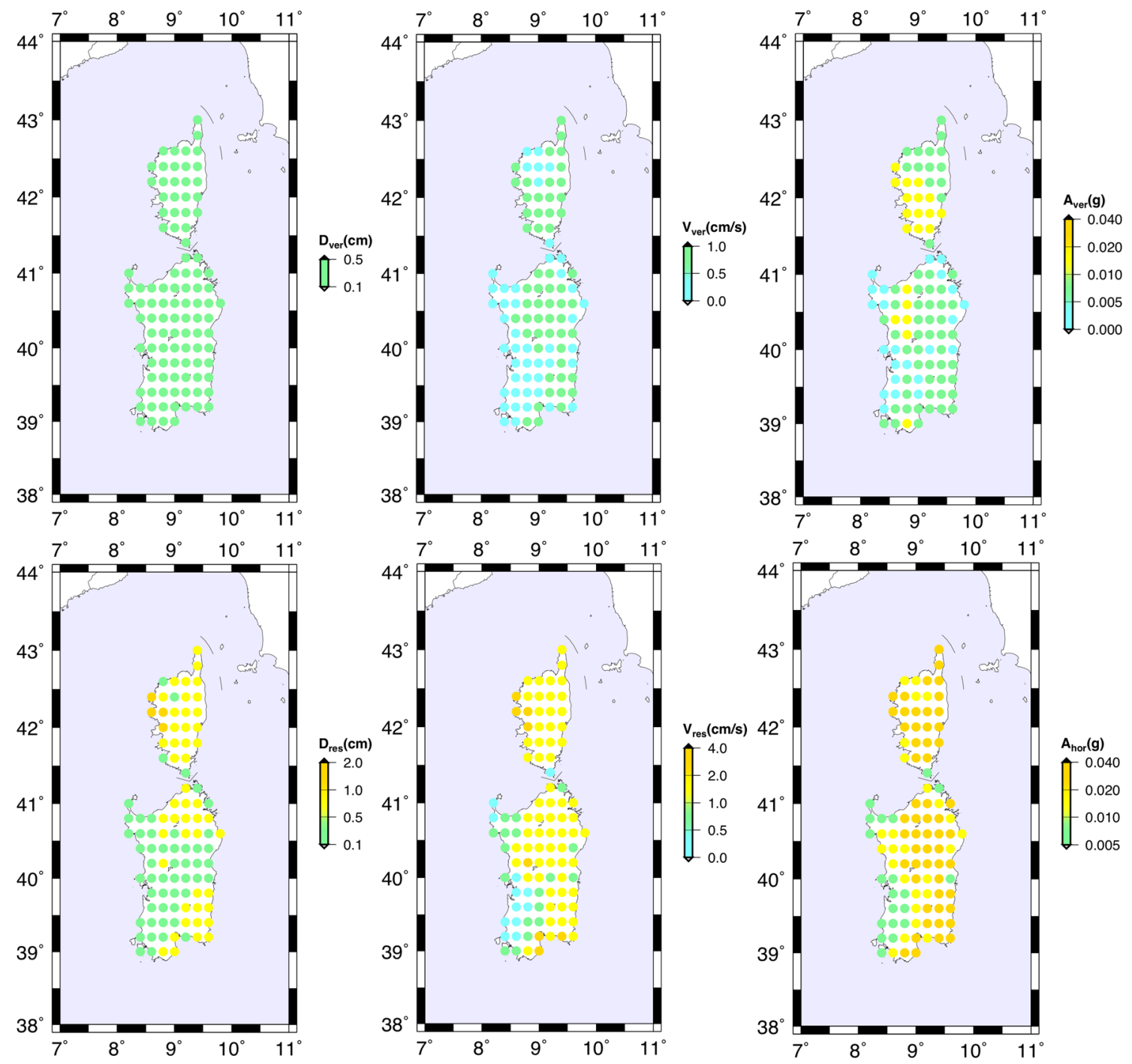

Fig. 5 Hazard maps at $1 \mathrm{~Hz}$ cut-off frequency obtained applying $M_{\text {design }}=5.5$ to the seismogenic nodes (color figure online)

Acknowledgements E. Brandmayr was funded by a Geoscience research grant by Centro Interdisciplinare Linceo "Beniamino Segre" of Accademia Nazionale dei Lincei.

Funding Open access funding provided by Università degli Studi di Trieste within the CRUI-CARE Agreement.

\section{Declarations}

Ethical statement Authors of the manuscript "Neo-deterministic seismic hazard assessment of Corsica-Sardinia block" by Brandmayr E., Vaccari F., Panza, G.F. confirm that the manuscript: Is not submitted to another journal for simultaneous consideration. Is original and has not been published elsewhere in any form or language (partially or in full). Is not a part of a larger study. The manuscript is an independent and completed research. Results are obtained using the objective geophysical and seismological data available to the whole scientific community. No data, text, or theories by others are presented as if they were our own.
Open Access This article is licensed under a Creative Commons Attribution 4.0 International License, which permits use, sharing, adaptation, distribution and reproduction in any medium or format, as long as you give appropriate credit to the original author(s) and the source, provide a link to the Creative Commons licence, and indicate if changes were made. The images or other third party material in this article are included in the article's Creative Commons licence, unless indicated otherwise in a credit line to the material. If material is not included in the article's Creative Commons licence and your intended use is not permitted by statutory regulation or exceeds the permitted use, you will need to obtain permission directly from the copyright holder. To view a copy of this licence, visit http://creativecommons.org/licenses/by/4.0/.

\section{References}

Aki K, Richards PG (2002) Quantitative seismology. University Science Books 
Bath M (1973) Introduction to seismology. Wiley, New York

Bela J, Panza GF (2021) NDSHA - the new paradigm for RSHA - an updated review. Earth Sci Vietnam J. https://doi.org/10.1525/ 0866-7187/15925

Brandmayr E (2012) The geodynamics of the Mediterranean in the framework of the global asymmetric Earth: evidences from seismological and geophysical methods. PhD Thesis, University of Trieste.

Brandmayr E, Raykova RB, Zuri M, Romanelli F, Doglioni C, Panza GF (2010) The lithosphere in Italy: structure and seismicity. In: Marco B, Angelo P, Massimo M, Sandro C, Carlo D (eds) Virtual Explorer, vol 36, pp 1. https://doi.org/10.3809/jvirtex. 2009.00224

Brandmayr E, Vaccari F, Romanelli F, Vlahovic G, Panza GF (2021) Neo-deterministic seismic hazard maps of Kosovo. Vietnam J Earth Sci 43(4):418-427. https://doi.org/10.15625/2615-9783/ 16328

Carminati E, Doglioni C, Gelabert B, Panza GF, Raykova RB, Roca E, Sabat F, Scrocca D (2012) Evolution of the western mediterranean; regional geology and tectonics: phanerozoic passive margins, cratonic basins and global tectonic maps. In: Roberts DG, Bally AW (eds) Vol. 1c, chapter 12, pp 437-470. Elsevier. https://doi.org/10.1016/B978-0-444-56357-6.00011-1.

CEN (2004) EN-1998-1:2004-Eurocode 8: design of structures for earthquake resistance-Part 1: general rules, seismic actions and rules for buildings. European Committee for Standardization, Brussels

Gorshkov A, Kossobokov V, Soloviev A (2003) Recognition of earth-quake-prone areas. In: Keilis-Borok V, Soloviev A (eds) Nonlinear dynamics of the lithosphere and earthquake prediction. Springer, Heidelberg, pp 239-310

Gorshkov AI, Soloviev AA, Jimenez MJ, Garcia-Fernandez M, Panza GF (2010) Recognition of earthquake-prone areas $(M \geq 5.0)$ in the Iberian Peninsula. Springer Rend Fis Acc Lincei 21:131-162

Gorshkov A, Panza GF, Soloviev A, Brandmayr E (2021) On the seismic potential of the Corsica-Sardinia block. Rend Fis Acc Lincei (in press). https://doi.org/10.1007/s12210-021-01014-z

Kennett BL, Engdahl ER (1991) Traveltimes for global earthquake location and phase identification. Geophys J Int 105(2):429-465

Martinez MD, Lana X, Guinto ER (2009) Elasto-anelastic regional structures of the crust and upper mantle beneath the Mediterranean basin derived from uncoupled casual inversion of rayleigh wave attenuation coefficient and group velocities. Geophysical research abstracts 11, EGU2009-2420

Martinez MD, Lana X, Guinto ER (2010) Shear-wave attenuation tomography of the lithosphere-asthenosphere system beneath the Mediterranean region. Tectonophysics 481:51-67

Meletti C, Galadini F, Valensise G, Stucchi M, Basili R, Barba S, Boschi E (2008) A seismic source zone model for the seismic hazard assessment of the Italian territory. Tectonophysics 450(1-4):85-108

Meletti C, Camassi R, Castelli V (2021) A reappraisal of the seismicity of Sardinia, Italy. Seismol Res Lett. https://doi.org/10.1785/ 0220200255
Minzoni N (1991) Geodynamic evolution of the Hercynian Sardinian-Corsican Massif: the relationships with the CalabrianPeloritan Arc. Tectonophysics 191(3-4):429-434

Panza GF, Bela J (2020) NDSHA: a new paradigm for reliable seismic hazard assessment. Eng Geol. https://doi.org/10.1016/j. enggeo.2019.105403

Panza GF, Romanelli F, Vaccari F (2001a) Seismic wave propagation in laterally heterogeneous anelastic media: theory and applications to seismic zonation. In: Advances in geophysics (Vol. 43, pp. 1-95). Elsevier

Panza GF, Romanelli F, Vaccari F (2001b) Seismic wave propagation in laterally heterogeneous anelastic media: theory and applications to seismic zonation. Adv Geophy 43:1-95 (Elsevier)

Panza GF, Peccerillo A, Aoudia A, Farina B (2007) Geophysical and petrological modeling of the structure and composition of the crust and upper mantle in complex geodynamic settings: the Tyrrhenian Sea and surroundings. Earth Sci Rev 80:1-46

Panza GF, La Mura C, Peresan A, Romanelli F, Vaccari F (2012) Seismic hazard scenarios as preventive tools for a disaster resilient society. Adv Geophys 53:93-165

Panza GF, Kossobokov VG, Laor E, De Vivo B (2021) Earthquakes and sustainable infrastructure (1st edition): neodeterministic (NDSHA) approach guarantees prevention rather than cure. Elsevier, pp.672. (ISBN: 9780128235416, 9780128235034)

Parvez IA, Romanelli F, Panza GF (2011) Long period ground motion at bedrock level in Delhi city from Himalayan earthquake scenarios. Pure Appl Geophys 168(3-4):409-477

Pondrelli S, Visini F, Rovida A, D'Amico V, Pace B, Meletti C (2020) Style of faulting of expected earthquakes in Italy as an input for seismic hazard modeling. Nat Hazard 20(12):3577-3592

Postpischl D (1985) Catalogo dei terremoti Italiani dall'anno 1000 al 1980. Progetto Finalizzato Geodinamica. Quaderni De La Ricerca Sci 114((2B)):239 ((in Italian))

Raykova RB, Panza GF (2010) The shear-wave velocity structure of the lithosphere-asthenosfhere system in the Iberian area and surroundings. Springer Rend Fis Acc Lincei 21:183-231

Rovida A, Locati M, Camassi R, Lolli B, Gasperini P (2020) The Italian earthquake catalogue CPTI15. Bull Earthq Eng. https://doi. org/10.1007/s10518-020-00818-y

Rovida A, Locati M, Camassi R et al (2021) Catalogo Parametrico dei Terremoti Italiani (CPTI15), versione 3.0. Istituto Nazionale di Geofisica e Vulcanologia (INGV). https://doi.org/10.13127/ CPTI/CPTI15.3

Rugarli P, Vaccari F, Panza GF (2019) Seismogenic nodes as a viable alternative to seismogenic zones and observed seismicity for the definition of seismic hazard at regional scale. Vietnam J Earth Sci 41:289-304

Publisher's Note Springer Nature remains neutral with regard to jurisdictional claims in published maps and institutional affiliations. 